\title{
STRATEGI PERENCANAAN PENGADAAN SEDIAAN FARMASI PADA BEBERAPA APOTEK DI KABUPATEN GIANYAR
}

\author{
Ni Made Atika Saraswati ${ }^{1 *}$, I Made Agus Gelgel Wirasuta ${ }^{1}$ \\ ${ }^{1}$ Program Studi Farmasi, Fakultas Matematika dan Ilmu Pengetahuan Alam, \\ Universitas Udayana \\ *E-mail: atikasaraswati65@gmail.com
}

\begin{abstract}
ABSTRAK
Perencanaan merupakan kegiatan dalam pemilihan jenis, jumlah, dan harga dalam rangka pengadaan dengan tujuan mendapatkan jenis dan jumlah yang sesuai dengan kebutuhan dan anggaran, serta menghindari kekosongan obat. Penelitian ini bertujuan untuk mengetahui strategi perencanaan yang digunakan oleh beberapa apotek di Kabupaten Gianyar. Jenis penelitian ini adalah penelitian observasional (non eksperimental) dan bersifat deskriptif kualitatif dengan pendekatan waktu cross sectional yaitu penelitian yang pengukurannya dilakukan pada suatu saat tertentu saja atau sekaligus pada suatu saat (point time approach). Apotek X, Apotek Y dan Apotek Z menerapkan metode konsumsi dalam perencanaan dan dapat meminimalisir terjadinya kerugian akibat barang expired.
\end{abstract}

Kata kunci: Perencanaan, Sediaan Farmasi Apoteker, Apotek

\begin{abstract}
Planning is an activity in the selection of types, quantities, and prices in the framework of procurement with the aim of getting the type and amount in accordance with the needs and budget, as well as avoiding the vacancy of the drug. This study aims to determine the planning strategy used by several pharmacies in Gianyar Regency. This type of research is observational research (nonexperimental) and is descriptive qualitative with a cross-sectional time approach that is research whose measurements are carried out at any given moment or at the same time (point time approach). $\mathrm{X}$ Pharmacy, Y Pharmacy and Z Pharmacy apply the consumption method in planning and can minimize losses due to expired goods.
\end{abstract}

Keywords: Planning, Pharmaceutical Preparation, Pharmacist, Pharmacy

\section{PENDAHULUAN}

Ilmu forensik adalah suatu proses ilmiah (didasari oleh ilmu pengetahuan) dalam menganalisis, mengumpulkan dan menghadirkan berbagai bukti dalam sidang yang bersangkutan dengan suatu kasus hukum [3]. Farmasi forensik merupakan penerapan dari ilmu farmasi ke dalam suatu hukum yang berlaku. Oleh karena itu, setiap hal yang menyangkut kefarmasian diatur oleh regulasi-regulasi negara dan pelaksanaannya harus sesuai dengan regulasi yang berlaku, termasuk standar pelayanan kefarmasian di apotek.

Standar pelayanan kefarmasian di Apotek diatur dalam Peraturan Menteri Kesehatan no 73 Tahun 2016 yang meliputi kegiatan pengelolaan apotek serta pelayanan klinis terhadap 
pasien. Tahapan pertama dalam pengelolaan apotek adalah perencanaan pengadaan sediaan farmasi. Perencanaan merupakan kegiatan dalam pemilihan jenis, jumlah, dan harga dalam rangka pengadaan dengan tujuan mendapatkan jenis dan jumlah yang sesuai dengan kebutuhan dan anggaran, serta menghindari kekosongan obat [4].

Perencanaan sediaan farmasi, alat kesehatan dan bahan medis habis pakai (BMHP) merupakan tahap awal untuk menetapkan jenis serta jumlah sediaan farmasi, alat kesehatan dan BMHP yang sesuai dengan kebutuhan. Tujuan dari perencanaan ini adalah mendapatkan perkiraan jenis dan jumlah sediaan sediaan farmasi, alat kesehatan dan BMHP yang mendekati kebutuhan; meningkatkan penggunaan sediaan farmasi, alat kesehatan dan BMHP secara rasional; menjamin ketersediaan sediaan farmasi, alat kesehatan dan BMHP; menjamin stok sediaan farmasi, alat kesehatan dan BMHP tidak berlebih; efisiensi biaya; memberikan dukungan data bagi estimasi pengadaan, penyimpanan dan biaya distribusi sediaan farmasi, alat kesehatan dan BMHP. Perencanaan untuk pengadaan sediaan farmasi, alat kesehatan dan BMHP melalui beberapa proses yaitu mulai dari persiapan, pengumpulan data, penetapan jenis dan jumlah yang direncanakan sesuai metode perhitungan kebutuhan, evaluasi perencanaan, revisi rencana kebutuhan obat dan apotek yang bekerjasama dengan BPJS diwajibkan untuk mengirimkan RKO yang sudah disetujui oleh pimpinan apotek melalui aplikasi E-Monev [1]. Setelah proses perencanaan telah ditetapkan maka akan dilanjutkan dengan pengadaan.

Pengadaan sediaan farmasi, alat kesehatan dan BMHP di apotek dilaksanakan dengan pembelian. Pembelian merupakan suatu metode penting untuk mencapai keseimbangan yang tepat antara mutu dan harga. Apabila ada dua atau lebih pemasok, apoteker harus mendasarkan pada kriteria berikut: mutu produk (kualitas produk terjamin ada NIE/Nomor Izin Edar), reputasi produsen (distributor berijin dengan penanggungjawab Apoteker dan mampu memenuhi jumlah pesanan), harga, berbagai syarat, ketepatan waktu pengiriman (lead time cepat), mutu pelayanan pemasok, dapat dipercaya, kebijakan tentang barang yang dikembalikan, dan pengemasan [1]. Untuk menjamin kualitas Pelayanan Kefarmasian maka pengadaan Sediaan Farmasi harus melalui jalur resmi sesuai ketentuan peraturan perundang-undangan [2]. 
Sementara itu, pengadaan sediaan farmasi di apotek secara umum memiliki alur seperti yang tertera pada Gambar 1 dengan memperhatikan hal-hal berikut [1]

1. Sediaan farmasi diperoleh dari Pedagang Besar Farmasi (PBF) yang memiliki izin.

2. Alat Kesehatan dan BMHP diperoleh dari Penyalur Alat Kesehatan (PAK) yang memiliki izin.

3. Terjaminnya keaslian, legalitas dan kualitas setiap sediaan farmasi, alat kesehatan dan BMHP yang dibeli.

4. sediaan farmasi, alat kesehatan dan BMHP yang dipesan datang tepat waktu.

5. Dokumen terkait sediaan farmasi, alat kesehatan dan BMHP mudah ditelusuri

6. Sediaan farmasi, alat kesehatan dan BMHP lengkap sesuai dengan perencanaan

Berdasarkan tujuan dari perencanaan pengadaan diharapkan bahwa pelaksanaan perencanaan di apotek telah berjalan sesuai dengan regulasi yang ada dan tidak menimbulkan kerugian akibat banyaknya persediaan yang tidak terjual dan akhirnya mencapai expired date. Oleh karena itu dilakukan observasi pada beberapa apotek di Kabupaten Gianyar untuk mengetahui strategi perencanaan yang digunakan guna mencegah terjadinya kerugian akibat persediaan yang mengalami expired.

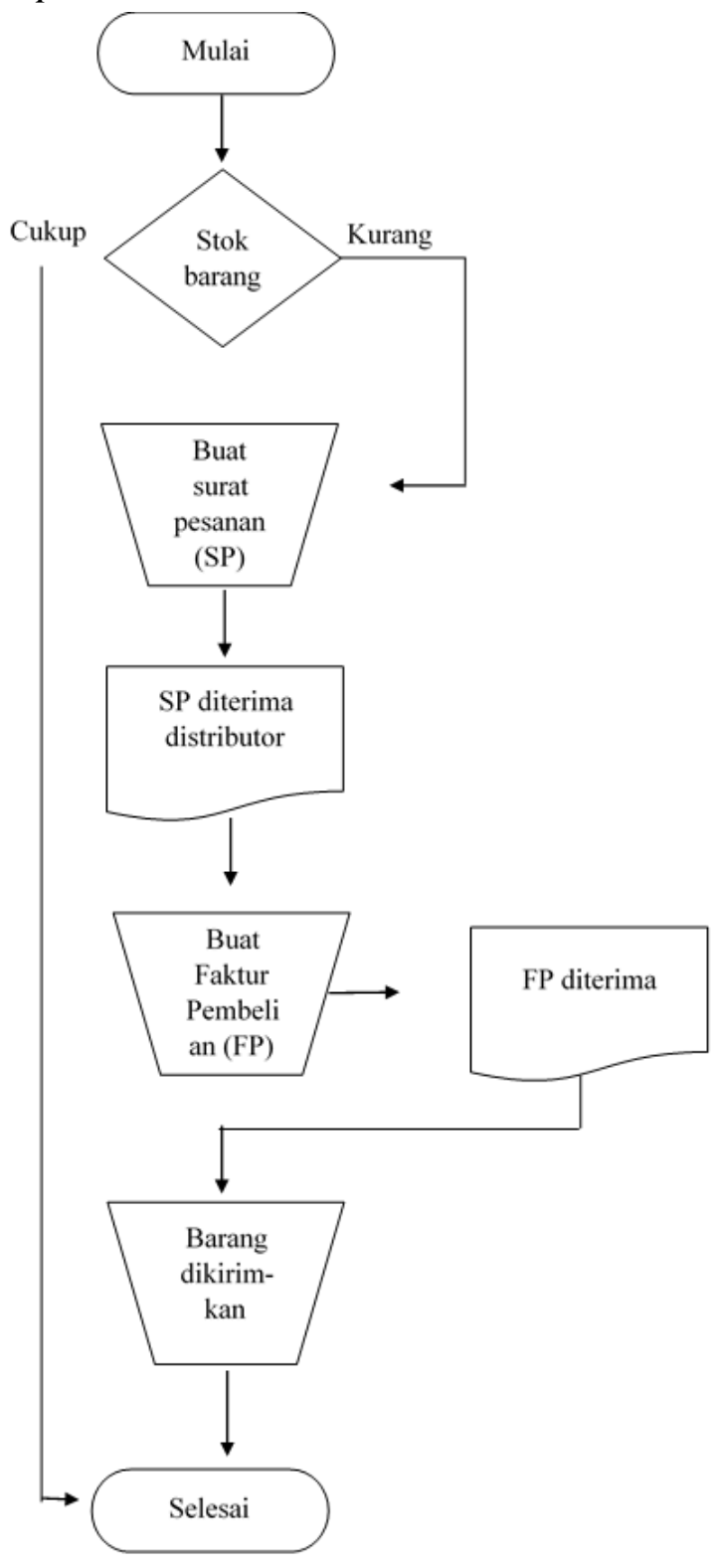

Gambar 1. Flowchart Prosedur Pengadaan Barang [6] 


\section{METODE PENELITIAN}

Jenis penelitian ini adalah penelitian observasional (non eksperimental) dan bersifat deskriptif kualitatif dengan pendekatan waktu cross sectional yaitu pengumpulan data dilakukan dengan wawancara yang berkaitan dengan metode perencanaan pengadaan apotek sesuai dengan Permenkes RI No 73 tahun 2016 dan dilakukan penelusuran dokumen secara retrospektif untuk melihat persentase modal atau dana yang tersedia dengan keseluruhan yang sesungguhnya dibutuhkan dan perbandingan antara jumlah item obat yang ada dalam perencanaan dengan jumlah item obat dalam kenyataan pemakaian pada rentang bulan Januari-Mei 2020. Pengolahan data akan dilakukan dengan menyajikan hasil wawancara berupa table dan dilakukan perbandingan antar sampel pada table tersebut. Penelitian yang pengukurannya dilakukan pada suatu saat tertentu saja atau sekaligus pada suatu saat (point time approach). Populasi penelitian ini adalah apotek wilayah Kabupaten Gianyar. Sampel dari penelitian ini adalah 1 apotek jejaring (Apotek X), 1 apotek mandiri (Apotek Y) dan 1 apotek dengan praktek dokter (Apotek Z). Sistem pengumpulan data dilakukan dengan wawancara yang berkaitan dengan metode perencanaan pengadaan apotek sesuai dengan Permenkes RI
No 73 tahun 2016 dan dilakukan penelusuran dokumen secara retrospektif untuk melihat persentase modal atau dana yang tersedia dengan keseluruhan yang sesungguhnya dibutuhkan dan perbandingan antara jumlah item obat yang ada dalam perencanaan dengan jumlah item obat dalam kenyataan pemakaian pada rentang bulan Januari-Mei 2020. Pengolahan data akan dilakukan dengan menyajikan hasil wawancara berupa table dan dilakukan perbandingan antar sampel pada table tersebut.

\section{HASIL DAN PEMBAHASAN}

Dalam membuat perencanaan pengadaan Sediaan Farmasi, Alat Kesehatan, dan Bahan Medis Habis Pakai perlu diperhatikan pola penyakit, pola konsumsi, budaya dan kemampuan masyarakat [2]. Peran apoteker sangat penting dalam melakukan perencanaan agar meningkatkan keberhasilan penjualan sediaan serta meningkatnya omset dari apotek yang dikelola. Berdasarkan observasi yang telah dilakukan, didapatkan data yang telah tertera pada Tabel 1.

\section{Metode Perencanaan}

Metode dan strategi perencanaan dapat ditujukan untuk penggunaan, untuk menyiapkan dan 
menyesuaikan biaya, perencanaan dan pengembangan layanan.

Data pada table 1 menunjukkan bahwa ketiga apotek menggunakan menggunakan metode konsumsi. Metode konsumsi didasarkan pada data konsumsi sediaan farmasi dengan dasar perhitungan analisa data konsumsi sediaan farmasi periode sebelumnya [1]. Berdasarkan hasil wawancara, penggunaan metode konsumsi ditujukan agar barang yang didaftarkan pada proses perencanaan dapat terdistribusikan dengan baik karena telah disesuaikan dengan pola konsumsi dari masyarakat yang pernah membeli sediaan farmasi di apotek tersebut. Dengan melakukan penyesuaian ini maka dapat menekan jumlah barang yang expired sebelum terjual. Metode yang digunakan dalam perencanaan akan mempengaruhi nilai omset yang diperoleh dari apotek tersebut. Semakin baik strategi yang digunakan oleh apoteker dalam mengelola apotek maka semakin banyak omset yang diperoleh.

Dalam menyusun perencanaan dengan metode konsumsi, seorang apoteker perlu memperhatikan hal-hal berikut [1].

a. Pengumpulan dan pengolahan data. Data yang diperlukan diantaranya daftar nama sediaan farmasi, stok awal, penerimaan, pengeluaran, sisa stok, daftar nama sediaan farmasi hilang; rusak dan kadaluwarsa kekosongan sediaan farmasi, pemakaian rata-rata per tahun, waktu tunggu, stok pegaman dan pola kunjungan

b. Analisa data untuk informasi dan evaluasi

c. Perhitunan perkiraan kebutuhan sediaan farmasi

d. Penyesuaian jumlah kebutuhan Sediaan Farmasi dengan alokasi dana

\section{Kerugian akibat barang expired}

Berdasarkan hasil wawancara, barang yang akan mengalami expired dapat dikembalikan ke pihak distributor atau PBF dengan ketentuan berdasarkan kebijakan dari masingmasing pihak. Hal ini merupakan kesepakatan pula antara pihak PBF dengan apotek yang bersangkutan sehingga ketentuan waktu pengembalian bisa berbeda-beda antar PBF. Apotek Z pada periode JanuariMei memperoleh kerugian dikarenakan kurang dilakukan pengecekan pada saat itu sehingga barang sudah tidak dapat dikembalikan ke pihak distributor atau PBF. Dengan menerapkan metode konsumsi, kerugian akibat barang expired dapat diminimalisir karena barang yang disediakan memiliki persentase yang tinggi sebagai barang fast moving dibandingkan dengan barang yang slow moving. Obat yang 
sering keluar (fast moving) harus selalu disediakan di Apotek, dan obat yang jarang keluar (slow moving) perlu dipertimbangkan untuk perencanaan pengadaannya supaya tidak terjadi pemborosan obat rusak atau obat ED karena terlalu lama disimpan di gudang. Selain itu tim perencanaan pengadaan obat juga harus menyeimbangkan antara dana apotek dengan pembelian. Supaya apotek tidak merugi karena pembelian lebih besar dari pada dana yang dipunyai apotek [4]. Sehingga, Apotek X, Apotek Y dan Apotek Z telah memahami kebutuhan konsumsi dari masyarakat yang berada disekitar apotek. Pelaksanaan strategi yang baik dalam melakukan perencanaan berkaitan dengan farmasi forensik yaitu memerlukan penerapan ilmuilmu kefarmasian dalam pelaksanaannya oleh apoteker pengelola apotek. Adapun ilmu yang diperlukan adalah manajemen farmasi dan farmakoepidemiologi. Pelaksanaan manajemen farmasi tidak hanya berfokus pada bagaimana melakukan pengelolaan tetapi juga memerlukan pemahaman mengenai sediaan farmasi, alat kesehatan dan bahan medis habis pakai sehingga penyusunan strategi perencanaan dapat berhasil dilakukan. Penerapan ilmu farmakoepidemiologi diperlukan untuk mengetahui pola penyakit dan pola konsumsi obat masyarakat. Pengumpulan data masyarakat dapat memberikan dan melengkapi informasi terkait gambaran epidemiologi suatu penyakit dan pemantauan pelaksanaan program kesehatan bagi para praktisi atau klinisi [5]. Oleh karena itu, hal yang direncanakan telah sesuai dengan kebutuhan masyarakat dan dapat meningkatkan keberhasilan stratergi perencanaan.

Tabel 1. Hasil Observasi Apotek

\begin{tabular}{|c|c|c|c|}
\hline \multirow{2}{*}{ Indikator } & \multicolumn{3}{|c|}{ Sampel } \\
\hline & Apotek X & Apotek Y & Apotek Z \\
\hline Metode Perencanaan & Konsumsi & Konsumsi & Konsumsi \\
\hline Kerugian Expired & Rp. 0,- & Rp 0,- & Rp. 300.000 \\
\hline Rata-rata Omset per bulan & Rp. 300.000 .000 & $\begin{array}{l}\text { Data merupakan } \\
\text { rahasia }\end{array}$ & Rp. 120.000 .000 \\
\hline $\begin{array}{l}\text { Persentase barang fast } \\
\text { moving }\end{array}$ & $85 \%$ & $70 \%$ & $60 \%$ \\
\hline $\begin{array}{l}\text { Persentase barang slow } \\
\text { moving }\end{array}$ & $15 \%$ & $30 \%$ & $40 \%$ \\
\hline
\end{tabular}




\section{KESIMPULAN}

Strategi perencanaan pengadaan merupakan hal yang penting untuk diperhatikan dalam mengelola apotek. Metode konsumsi adalah metode yang dipakai oleh Apotek X, Apotek Y dan Apotek $\mathrm{Z}$ dengan hasil dapat meminimalkan terjadinya barang expired. Penerapan ilmu farmasi forensik dapat mendukung keberhasilan untuk pengelolaan apotek agar pelaksanaan dari perencanaan sesuai dengan regulasi yang telah ditetapkan.

\section{UCAPAN TERIMAKASIH}

Pada kesempatan ini penulis mengucapkan terimakasih kepada segenap pihak baik dari Program Studi Farmasi, Fakultas MIPA Universitas Udayana,pihak Apotek X, Apotek Y, dan Apotek $\mathrm{Z}$ yang berada di Kabupaten Gianyar atas kesempatan observasi yang diberikan hingga terselesaikannya peneitian ini.

\section{DAFTAR PUSTAKA}

[1] Kemenkes RI. 2019. Petunjuk Teknis Standar Pelayanan Kefarmasian di Apotek. Jakarta:
Kementrian Kesehatan Republik Indonesia.

[2] Kemenkes RI. 2016. Peraturan Menteri Kesehatan Republik Indonesia Nomor 73 Tahun 2016 Tentang Standar Pelayanan Kefarmasian Di Apotek. Jakarta: Kementrian Kesehatan Republik Indonesia.

[3] Maramis , M. R. 2015. Peran Ilmu Forensik Dalam Penyelesaian Kasus Kejahatan Seksual Dalam Dunia Maya (Internet). Jurnal Ilmu Hukum. 2(7): 42-53.

[4] Wijayanti, A dan C. Priyono, 2014. Analisa Pengadaan Obat dengan Metode ABC di Apotek Yudhistira. Indonesian Journal on Medical Science. 1(2): 17-22.

[5] Amiruddin, R. S. 2013. Kesehatan Masyarakat. Bogor: IPB Press.

[6] Triani, F. 2013. Laporan Praktek Kerja Profesi Apoteker Di Apotek Kimia Farma No.48 Jl. Matraman Raya No. 55 Jakarta Timur Periode 3 April 30 April 2013. Laporan Praktek Kerja Profesi Apoteker. Universitas Indonesia. 